This is an author produced version of a paper published in Journal of Applied Polymer Science.

This paper has been peer-reviewed but may not include the final publisher proof-corrections or pagination.

Citation for the published paper:

Carolin Menzel, Kristine Koch. (2014) Impact of the Coating Process on the Molecular Structure of Starch-Based Barrier Coatings. Journal of Applied Polymer Science. Volume: 131, Number: 23, pp. http://dx.doi.org/10.1002/app.41190.

Access to the published version may require journal subscription. Published with permission from: Wiley.

Standard set statement from the publisher:

This is the peer reviewed version of the following article: Menzel, C. and Koch, K. (2014), Impact of the coating process on the molecular structure of starch-based barrier coatings. J. Appl. Polym. Sci., 131, 41190. Which has been published in final form at 10.1002/app.41190. This article may be used for non-commercial purposes in accordance With Wiley Terms and Conditions for selfarchiving

Epsilon Open Archive http://epsilon.slu.se 


\section{Impact of the coating process on the molecular structure of starch-based barrier 2 coatings}

Carolin Menzel", Kristine Koch

Department of Food Science, Uppsala BioCenter, Swedish University of Agricultural Sciences, Box 7051, 5 SE-75007 Uppsala, Sweden Correspondence to: Carolin Menzel (E-mail: carolin.menzel@slu.se)

\section{ABSTRACT}

Molecular analysis of starch structure can be used to explain and predict changes in physical properties, such as water vapor and oxygen barrier properties in packaging materials. Solution casting is a widely used technique to create films from starch formulations. This study compared the molecular properties of these standard films with those of experimental coatings applied to paper in laboratory-scale and pilot-scale trials, with all three techniques using the same starch formulation. The results revealed large differences in molecular structure, i.e., cross-linking and hydrolysis, between films and coatings. The main differences were due to the shorter drying time allowed to laboratory-scale coatings and the accelerated drying process in pilot trials owing to the high energy output of infrared dryers. Furthermore, surface morphology was highly affected by the coating technique used, with a rougher surface and many pinholes occurring in pilot-scale coatings, giving lower water vapor permeability than laboratoryscale coatings.

KEYWORDS starch, film forming, coating, solution cast, molecular structure, citric acid, drying, processing

\section{INTRODUCTION}

There is increasing demand for green packaging materials in the world, driven by industrial growth and trends for environmentally friendly packaging. ${ }^{1}$ The world demand for food packaging is expected to grow about $2.5 \%$ per year. ${ }^{2}$ The expected production capacity of bio-plastics is ecpected to grow fivefold from 2011 to 2016 as the largest sector in packaging. ${ }^{3}$ Hence, there have been intensive investigations on bio-based materials, especially from bio-polymers, for packaging purposes. Conventional food packaging consists of multi-layer films of synthetic plastics and adhesives to provide barrier properties, allow color printing, and bind all layers together. From an environmental point of view, it is desirable to replace these coatings with renewable types. Several bio-polymers such as starch, poly-lactic acid, and polyhydroxybutyrate can replace synthetic plastics such as polyethylene terephthalate or polystyrene plastics. ${ }^{4,5}$ In 2010, starch represented the second largest sector of the global bio-plastic packaging 
coatings because of its abundance and ability to form a network structure. The possibility of using starch as a base in new materials has been extensively researched since the 1950s. ${ }^{7}$ Starch is commonly plasticized with glycerol to overcome its brittleness and several chemical modifications can be used to improve the hydrophilic character of starch. Due to its structure of chains of $(1 \rightarrow 4)$ linked $\alpha$-glucan units and numerous free hydroxyl groups, various chemical modifications such as acid hydrolysis, oxidation, ${ }^{8}$ cross-linking, ${ }^{9}$ and acetylation ${ }^{10,11}$ can be applied to obtain desired physical properties. Regarding barrier properties for food packaging, the most critical compounds are water vapor and oxygen, since these compounds can permeate through the packaging material and alter the food quality. In recent studies, cross-linking with citric acid (CA) has been cited as a promising additive to improve the thermal and barrier properties of starch films. ${ }^{9,12,13}$ In those studies, changes in molecular structure due to acid hydrolysis and cross-linking by adding CA were analyzed using solution-cast films. ${ }^{12}$ In a study by Olsson et al., ${ }^{9}$ starch films containing up to 30pph CA reduced moisture content, diffusion coefficient and water vapor permeability confirming previous findings. ${ }^{13,14}$ Molecular characterization studies on the same films confirmed that high CA content and high temperature curing increased cross-linking reactions, but that hydrolysis of starch occurred simultaneously. To prevent severe hydrolysis of starch films at high CA content and preserve improved barrier properties at the same time, $\mathrm{pH}$ adjustments to the starch formulation before drying were tested. It was shown that at $\mathrm{pH} \mathrm{4,} \mathrm{starch} \mathrm{hydrolysis} \mathrm{was} \mathrm{stopped,} \mathrm{while}$ cross-linking still occurred. In addition, gas barrier properties, i.e., oxygen and water vapor permeability, showed a minimum at pH 4 measured on laboratory-scale coated paper based on the same starch solution and prepared under comparable drying conditions. ${ }^{9,15}$ However, to the best of our knowledge, there are no studies comparing the impact of the coating process on the molecular structure of starch coated on paper or paperboard, either in the laboratory or at pilot scale, relative to solution-cast films.

To test a new starch formulation as a barrier coating in a food packaging application, pilot-scale trials are normally carried out in industry. However, such trials are very expensive and time-consuming. As an alternative, laboratory-scale experiments can be used to study desired parameters. The most common film formation technique used at laboratory scale is casting, where the film-forming solution is cast on a non-adhesive surface and the solvent is evaporated. Different parameters such as drying temperature and relative humidity $(\mathrm{RH})$ influence the film properties. For instance, it has been shown that in glycerolplasticized amylopectin films, increasing $\mathrm{RH}$ results in higher relative crystallinity during film formation. ${ }^{16}$ Throughout the drying process, hydrogen bonds are formed between the bio-polymers and/or plasticizers and the film structure is generated. ${ }^{17}$ The longer film formation takes, the longer time there is for a film component to phase-separate and crystallize. ${ }^{18}$ However, drying kinetics in industry can differ substantially from laboratory-scale conditions. For example, in industrial applications the drying strategy depends on the machine speed, amount of layers applied and the drying conditions, i.e., temperature and relative humidity in the building. There is only a short time between the application of the coating on the carrier material and the final immobilization point where water evaporates and the network structure is created. Therefore, it is crucial to study and understand the relationship between processing technique, molecular structure, and material properties when seeking to develop new functional packaging coatings. 
The objectives of this study were terefore: 1 ) to find suitable methods to analyze the molecular structure of starch in paper coatings, 2) to determine the impact of the coating process parameters on the molecular and barrier properties of starch-based coatings, and 3) to compare the molecular structure of solution-cast starch films and laboratory-scale coated papers with that of industrially produced starch coatings from a pilot trial. Experimental parameters for the pilot trial were chosen according to a previous study, ${ }^{15}$ where laboratory-scale coated papers showed a minimum in water vapor transmission rate (WVTR) and no hydrolysis when the $\mathrm{pH}$ was kept at 4 for a CA-starch formulation. That study showed that molecular changes in solution-cast films cannot be directly related to barrier properties that are generally measured on coated papers. There were large differences in molecular structure between solution-cast films and laboratory-scale coated papers. No hydrolysis was detectable due to the shorter drying time applied to the laboratory-scale coatings. The pilot-scale coatings also showed no hydrolysis, but demonstrated a higher degree of cross-linking compared with the laboratory-scale coated papers and solution-cast films. At pilot scale, the drying process is accelerated by the high energy output of infrared dryers, which evaporates the water in a very short time and initiates the esterification and finally cross-linking reaction. The higher water vapor permeability in pilot-scale coatings has been attributed to a rougher and more uneven surface and large visible pinholes compared with laboratory-scale coatings due to the coating technique applied.

\section{EXPERIMENTAL}

\section{Materials}

Hydroxypropylated and oxidized potato starch (Solcoat 155 and Solcoat P55) was kindly provided by Solam (Kristianstad, Sweden). According to the supplier, this commercial starch contains about $79 \%$ amylopectin and $21 \%$ amylose, with a degree of substitution of 0.11 with respect to hydroxypropylation. A different starch was used in the pilot trial because of the lower viscosity requirements in industrial applications and the higher solids content while boiling (30\% for Solcoat P55 instead of $20 \%$ as for Solcoat 155). The starch used in laboratory coatings had a viscosity of $180 \mathrm{cP}$ at $20 \%$ solids content, Brookfield LVDV $100 \mathrm{rpm}$, and $50^{\circ} \mathrm{C}$, for jet cooked starch whereas the pilot-scale starch had a viscosity of $30 \mathrm{cP}$ under similar conditions. The difference between the two starches (Figures 1 and 2) is due to higher oxidation in Solcoat P55 to gain lower viscosity set by the amount of hypochlorite during modification. All reagents and solvents (sodium hydroxide, phenol, sulfuric acid 95-97\%, double supplemented iodine, anhydrous glucose, potassium hydroxide, boric acid, copper(II)sulfate-5 hydrate) used for analyses were of analytical grade and were purchased from Merck, Germany, except for anhydrous citric acid and sodium borate-10hydrate, which were supplied by Sigma-Aldrich Inc., ST. Louis, 107 MO, USA.

\section{Preparation of starch films and starch coatings}

\section{Solution-cast starch films}


110

111

112

113

114

115

116

117

118

119

120

121

122

123

124

125

126

127

128

129

130

131

132

133

134

135

136

137

138

139

140

141

142

143

The preparation of solution-cast starch films is described in detail elsewhere. ${ }^{9}$ In brief, a $10 \%(w / w)$ starch (Solcoat 155) solution was gelatinized in a boiling water bath, cooled to room temperature and 30 parts CA per 100 parts of dry starch (pph) were added. The CA-containing starch solution was then adjusted to different $\mathrm{pH}$ values $(2,4$ and 6.5) using $10 \mathrm{M} \mathrm{NaOH}$ solution, cast in Petri dishes and dried at $70{ }^{\circ} \mathrm{C}$ for $5 \mathrm{~h}$. The dried solution-cast films were heat-treated (cured) for $10 \mathrm{~min}$ at $150{ }^{\circ} \mathrm{C}$.

\section{Laboratory-scale starch coatings on paper}

The laboratory-scale starch coatings were prepared according to Olsson et al. ${ }^{15} \mathrm{The} \mathrm{pH}$-adjusted starch (Solcoat 155) solutions described above were coated in double layers on Super Perga WS Parchment $70 \mathrm{~g} / \mathrm{m}^{2}$ paper (Nordic Paper Greåker, Norway) using a bench coater and a wire-wound bar (K202 Control Coater, RK Coat Instrument Ltd., Royston, UK). The first layer was dried before applying the second layer and both coated layers were dried at either $70^{\circ} \mathrm{C}$ or $150^{\circ} \mathrm{C}$ for $90 \mathrm{~s}$. The coat weight was measured according to Olsson et al. ${ }^{15}$ In brief, the difference in weight between coated and uncoated papers was measured after conditioning at $23^{\circ} \mathrm{C}$ and $50 \% \mathrm{RH}$ for at least $24 \mathrm{~h}$. The resulting coat weight was between 15 and $18 \mathrm{~g} / \mathrm{m}^{2}$.

\section{Pilot-scale starch coatings on paper}

Pilot-scale coating was carried out using an industrial machine (UMV Coating Systems AB, Säffle, Sweden) and a starch (Solcoat P55) formulation with pH adjusted to 4 . The coatings were applied either as single or double layers. The machine parameters were: machine speed $400 \mathrm{~m} / \mathrm{min}$, coating technique hard tip, drying with infrared dryer at $150{ }^{\circ} \mathrm{C}$, followed by $60{ }^{\circ} \mathrm{C}$ at $35 \% \mathrm{RH}$, and a nominal evaporation rate of 673 $\mathrm{kg} / \mathrm{m} / \mathrm{h}$. The starch formulation consisted of $100 \mathrm{pph}$ starch and $30 \mathrm{pph} \mathrm{CA}$, adjusted to $\mathrm{pH} 4$ with $\mathrm{NaOH}$ and $0.01 \%(w / w)$ defoamer BIM 7640 (BIM Kemi Sweden AB).. Two commonly used and well-studied industrial clay fillers, 87pph kaolin filler (Barrisurf $\mathrm{LX}^{\mathrm{TM}}$, Imerys) and 3pph nanosized clay filler (Cloisite $\mathrm{Na}^{+} \mathrm{TM}$, Southern Clay Products Inc.), were added to improve barrier properties and develop a renewable starch formulation for industrial usage. The resulting coat weight was 6 and $11 \mathrm{~g} / \mathrm{m}^{2}$ for single and double coatings, respectively, on greaseproof paper Super Perga WS Parchment $70 \mathrm{~g} / \mathrm{m}^{2}$ (Nordic Paper Greåker, Norway).

\section{Extraction of starch from the coated paper}

A method to extract starch from the coated carrier material (paper) was developed in order to ensure a representative comparison of the molecular structure in solution-cast films and coated papers. Cut pieces of coated paper $(0.5 \times 0.5 \mathrm{~cm}, 0.1 \mathrm{~g})$ were either stirred in water or in $0.1 \mathrm{M}$ or $1 \mathrm{M} \mathrm{NaOH}$ for different periods ( $20 \mathrm{~min}, 5 \mathrm{~h}, 24 \mathrm{~h}$ ). The extract was filtered through $0.45 \mu \mathrm{m}$ filters. Starch content in terms of glucose concentration was measured according to the phenol-sulfuric acid method. ${ }^{19}$ The uncoated carrier material used as a blank was treated in a similar way.

\section{Molecular characterization of amylose and amylopectin}


144 Changes in amylose and amylopectin content were determined using a method described elsewhere. ${ }^{12}$

145 In brief, $25 \mathrm{mg}$ solution-cast film or $100 \mathrm{mg}$ starch-coated paper were dispersed in $5 \mathrm{~mL} 0.1 \mathrm{M} \mathrm{NaOH}$,

146 filtered through an $0.45 \mu \mathrm{m}$ filter, and a 1-mL aliquot was injected for size-exclusion chromatography on

147 a Sepharose CL-2B column (GE Healthcare, Uppsala, Sweden). Fractions of $1 \mathrm{~mL}$ were analyzed using a

148 combination of the phenol-sulfuric acid method and iodine staining. ${ }^{19,20}$ This permitted determination of

149 the starch concentration in the elution profile in terms of glucose equivalents using the phenol-sulfuric

150 acid reagent and determination of chain length in terms of wavelength at maximum absorbance using

151 iodine staining. Amylose molecules appear at higher wavelength numbers due to their longer chains. ${ }^{20,21}$

152 The experiment was performed in duplicate.

\section{Determination of weight-average molecular weight $\left(\mathrm{M}_{\mathrm{w}}\right)$}

154 Weight-average molecular weight $\left(\mathrm{M}_{\mathrm{W}}\right)$ was measured on solution-cast starch films and on extracted 155 starch from coatings, which were then dissolved in either $0.1 \mathrm{M} \mathrm{NaOH}$ solution or distilled water.

156 Therefore, about $25 \mathrm{mg}$ solution-cast films or $100 \mathrm{mg}$ starch-coated paper were suspended in $5 \mathrm{~mL}$ of 157 the respective solvent for $2 \mathrm{~h}$ and gently stirred using a magnetic stirrer. The $\mathrm{NaOH}$ suspensions were 158 kept at room temperature, while the water suspensions were heated to $70{ }^{\circ} \mathrm{C}$ in a water bath to dissolve 159 the starch. The solutions were filtered through a $0.45 \mu \mathrm{m}$ filter and directly injected $(75 \mu \mathrm{L})$ into a high160 performance size-exclusion chromatography (HPSEC) system coupled with a multi-angle laser-light 161 scattering (MALLS) detector and a refractive index (RI) detector, as described elsewhere. ${ }^{12}$ Furthermore, 162 a $950-\mu \mathrm{L}$ aliquot of the filtered water suspension was treated with $50 \mu \mathrm{L} 2 \mathrm{M} \mathrm{NaOH}$ to detect possible 163 changes in $\mathrm{M}_{\mathrm{w}}$ due to expected cross-linkage formation between CA and starch. The experiments were 164 performed in duplicate.

\section{Solubility in water}

166 Water solubility was determined as described elsewhere. ${ }^{12}$ In brief, the starch/water suspensions (about $1675 \mathrm{mg} / \mathrm{mL})$ was stirred for 2 days and then diluted $(1: 80, \mathrm{v} / \mathrm{v})$ and filtered before analyzing the starch 168 concentration using the phenol-sulfuric acid reagent. ${ }^{19}$ The corresponding glucose concentration was 169 calculated using a glucose standard calibration curve. The glucose concentration was corrected by a 170 factor of 0.9 , based on anhydroglucose units ( $\left.\mathrm{M}_{\mathrm{AGU}} 162 \mathrm{~g} / \mathrm{mol}\right)$ as the main subunits of starch. The 171 experiment was performed in duplicate.

\section{Titration with copper (II)-sulfate for CA di-ester determination}

173 Citric acid di-esters were determined according to the complexometric titration method of CA with 174 copper(II)-ions described by Graffmann et al., ${ }^{22,23}$ with small modifications as described elsewhere. ${ }^{12}$ In 175 brief, $300 \mathrm{mg}$ solution-cast starch film or $1 \mathrm{~g}$ starch-coated paper was weighed into a beaker and two 176 different treatments, direct titration and titration after hydrolysis, were carried out. Starch ester bonds 177 were hydrolyzed using $50 \mathrm{~mL} 0.1 \mathrm{M} \mathrm{KOH} \mathrm{(pH} \mathrm{>12).} \mathrm{In} \mathrm{both} \mathrm{treatments,} \mathrm{a} \mathrm{borax/boric} \mathrm{acid} \mathrm{buffer} \mathrm{(} \mathrm{pH} 8.5$ ) 178 was added and the starch samples were titrated with $0.02 \mathrm{M}$ copper(II)-sulfate solution. The content of 179 CA di-ester was calculated according to Menzel et al. ${ }^{12}$ The experiment was performed in triplicate. 
181 Scanning electron microscopy was carried out directly on film surfaces using an environmental tabletop

182 Hitachi TM-1000-mu-DeX instrument and an accelerating voltage of $15 \mathrm{keV}$, magnification x100.

Water vapor transmission rate of pilot-scale coatings compared with laboratory-scale coatings

Barrier properties in terms of WVTR were measured on laboratory-scale and pilot-scale coatings using ISO 2528 with silica gel as desiccant in tests carried out at $23{ }^{\circ} \mathrm{C}$ and $50 \% \mathrm{RH}$. The experiment was performed in duplicate.

\section{RESULTS AND DISCUSSION}

\section{Extraction of starch from the coated papers}

Pre-experiments were performed with the laboratory-scale and pilot-scale coated papers to ensure that the entire starch coating went into solution and that particles from the carrier material did not interfere with the analysis. It was found that $100 \mathrm{mg}$ coated material in $5 \mathrm{~mL} 0.1 \mathrm{M} \mathrm{NaOH}$, stirred for $20 \mathrm{~min}$ and subsequently filtered through a $0.45 \mu \mathrm{m}$ filter, was sufficient to recover $75-82 \%$ of the starch applied as a coating. The dissolved starch content was determined as glucose equivalents using phenol-sulfuric acid reagent and a glucose calibration curve. Longer time $(5 \mathrm{~h}, 24 \mathrm{~h}$ ) or higher alkali concentration (1 M $\mathrm{NaOH}$ ) did not increase solubility (data not shown). For the pilot-scale coatings, it was found that about $3 \%$ (by weight) of the uncoated carrier paper went into the $0.1 \mathrm{M} \mathrm{NaOH}$ solution and was recovered as glucose equivalents using phenol-sulfuric acid reagent. However, iodine staining showed no color formation and $M_{w}$ determined by HPSEC-MALLS-RI was lower than 40,000 g/mol, indicating that the dissolved molecules were probably low molecular weight starch molecules present within the carrier paper. In addition, the elution profile using size-exclusion chromatography of the dissolved part of the uncoated carrier material showed small molecules with no iodine staining eluting late in the chromatogram (Figure 1, elution fraction 135-160 mL). Therefore, these small molecules were considered not to interfere with further molecular analysis.

\section{Molecular changes in laboratory scale starch coatings compared with solution-cast starch films}

\section{Molecular characterization}

The solution-cast starch films are described in detail by Olsson et al. ${ }^{15}$ and were used as reference material for laboratory-scale starch coatings.

Molecular characterization of laboratory-scale coated starch films and solution-cast starch films revealed no changes in amylopectin and amylose distribution (relative absorbance curve and $\Lambda_{\max }$ values) between the laboratory-scale coated starch films at $\mathrm{pH} 2$ at different curing temperatures (non-cured 
and cured at $\left.150^{\circ} \mathrm{C}\right)$. However, with high temperature curing $\left(150^{\circ} \mathrm{C}\right)$ of the solution-cast starch films, the first eluting peak corresponding to amylopectin was strongly affected at different $\mathrm{pH}$ levels due to starch degradation (Figure $2 \mathrm{~b}$ ). For the laboratory-scale coated starch films no degradation of starch molecules was detected and hence no hydrolysis due to CA had taken place compared with the asreceived starch (Figure 2a). One explanation could be differences in the drying process of the coatings and films, as the curing time to produce laboratory-scale coated starch papers was substantially shorter (90 s) than that for solution-cast films (10 $\mathrm{min})$. In addition, it is reasonable to believe that heating the coated papers to the same temperature as the solution-cast films took a longer time due to the thickness of the material. It has been shown previously that high temperature promotes acid hydrolysis ${ }^{12,24,25}$ and that different drying conditions influence film formation and molecular structure in starch films. ${ }^{16,26}$ Hence, during the shorter drying time for the starch coatings, less starch was degraded compared with in the solution-cast films. It is important to consider the drying method applied to coatings and cast films in order to predict molecular changes in solution-cast films coated on paper in the laboratory, as well as coatings prepared under industrial conditions.

\section{$M_{w}$ determination in $0.1 \mathrm{M} \mathrm{NaOH}$ and water}

Starch from solution-cast films and laboratory-scale coated films were dissolved in $0.1 \mathrm{M} \mathrm{NaOH}$ to determine $\mathrm{M}_{\mathrm{W}}$ of the de-esterified starch molecules (Figure 3). Solution-cast films as described previously by Olsson et al. ${ }^{15}$ were used as reference. The $\mathrm{M}_{\mathrm{w}}$ of starch from coatings was between 6.3 and $8.0 * 10^{6} \mathrm{~g} / \mathrm{mol}$ for non-cured and $150{ }^{\circ} \mathrm{C}$ cured coatings, compared with $8.8^{*} 10^{6} \mathrm{~g} / \mathrm{mol}$ for asreceived starch. There were no significant differences ( $t$-test, $p>0.05$ ) between coatings prepared in the different conditions, i.e. neither $\mathrm{pH}$ nor high temperature curing affected $\mathrm{M}_{\mathrm{w}}$ of the starch applied as a coating on paper. This is in agreement with the results from molecular analysis of amylose and amylopectin showing no degradation of starch in laboratory-scale coated paper (Figure 2a). However, solution-cast starch films were strongly affected by $\mathrm{pH}$ and high temperature curing e.g., a decrease in $\mathrm{M}_{\mathrm{W}}$ with decreasing $\mathrm{pH}$ (Figure 3). Adjustment of the $\mathrm{pH}$ to higher values prevented acid hydrolysis even in cured films, as shown in a previous study. ${ }^{15}$

In addition, the $\mathrm{M}_{\mathrm{W}}$ of the water soluble starch extract of solution cast films and laboratory scale coatings was measured before and after subsequent de-esterification with $\mathrm{NaOH}$ (Table 1) and the solubility in water was determined (Figure 4).

Laboratory-scale coating on paper showed higher water solubility (63-80\%) than the reference solutioncast starch films (16-48\%, data from Olsson et al.). This could be due to a lower degree of cross-linking of starch molecules by CA in the laboratory-scale starch coatings compared with the solution-cast starch films, resulting in higher water solubility.

The $\mathrm{M}_{\mathrm{w}}$ of the water-soluble starch extracted from laboratory-scale coated papers was lowest for coatings prepared at $\mathrm{pH} 2\left(5.5^{*} 10^{6} \mathrm{~g} / \mathrm{mol}\right)$ and increased with increasing $\mathrm{pH}$ (Table 1$)$. There was no significant change in $\mathrm{M}_{\mathrm{W}}$ when coatings were cured at high temperature $\left(150^{\circ} \mathrm{C}\right)$. The $\mathrm{M}_{\mathrm{W}}$ of water- 
soluble starch was similar to that of de-esterified starch in $\mathrm{NaOH}$ (Figure 3), as anticipated from the high water solubility. Only coatings prepared at $\mathrm{pH} 2$ had a slightly lower $\mathrm{M}_{\mathrm{W}}$ in water (Table 1), although water alone also gave the highest water solubility.

Cross-linking of starch by $C A$ was detectable as a change in $\mathrm{M}_{\mathrm{W}}$ of the water-soluble starch after subsequent treatment with $\mathrm{NaOH}$ which induced hydrolysis of the ester bonds between one $\mathrm{CA}$ molecule and two starch molecules and hence reduced $\mathrm{M}_{\mathrm{w}}$ (Table 1). The laboratory-scale coated papers prepared at $\mathrm{pH} 2$ showed the highest $\mathrm{M}_{\mathrm{w}}$ decrease $\left(23 \%\right.$, or $26 \%$ for curing at $150{ }^{\circ} \mathrm{C}$ ) after $\mathrm{NaOH}$ treatment of the water-soluble starch. The $\mathrm{M}_{\mathrm{w}}$ decrease was lower for laboratory-scale coatings prepared at $\mathrm{pH} 4$ ( $6 \%$ non-cured, $16 \%$ cured) and pH 6.5 (6\% non-cured, $12 \%$ cured), indicating fewer CA cross-linkages in the water soluble starch extract. The cross-linking reaction, which is basically Fischer esterification, is catalyzed at low $\mathrm{pH}$ explaining the larger decrease in $\mathrm{M}_{\mathrm{W}}$ at $\mathrm{pH}$ 2. High-temperature curing of the coatings resulted in slightly higher $\mathrm{M}_{\mathrm{W}}$ decreases after $\mathrm{NaOH}$ treatment and hence a higher degree of cross-linking. In contrast, $\mathrm{M}_{\mathrm{w}}$ before and after de-esterification of water-soluble starch from solution-cast films was highly affected by both $\mathrm{pH}$-adjustment and curing, resulting in highly cross-linked films at $\mathrm{pH} 2$ ( $\mathrm{M}_{\mathrm{W}}$ decrease $\left.19 \%\right)$ and high temperature $\left(\mathrm{M}_{\mathrm{W}}\right.$ decrease $\left.85 \%\right)$, as described and discussed in previous reports. ${ }^{15}$

It was found that the $M_{W}$ and solubility of starch from solution-cast films and laboratory-scale coatings were differently affected. The difference in cross-linking might be due to the difference in the drying process, i.e. curing for $10 \mathrm{~min}$ or $90 \mathrm{~s}$, as discussed above with reference to the molecular distribution of amylose and amylopectin. However, even the short drying time that was applied to the coated papers was sufficient to initiate cross-linking between starch molecules in laboratory-scale coatings at all pH levels. In addition, the $\mathrm{M}_{\mathrm{W}}$ data showed that cross-linking of starch by CA took place, besides acid hydrolysis as described previously. ${ }^{12,15}$

\section{Citric acid di-ester determination in solution-cast starch films and laboratory-scale coated papers}

As described in previous reports, ${ }^{12}$ the titration of CA with copper (II) -sulfate can detect CA and monoesterified CA molecules. Hence, titration before and after hydrolysis shows the amount of CA molecules that are di-esterified and potentially cross-linked between different starch molecules. The CA di-ester content was expressed in terms of degree of di-esterification (DDE) for the solution-cast films (data from Menzel et al. ${ }^{12}$ ) and the laboratory-scale coated films (Figure 5).

The amount of di-esterified CA ranged between $1 \%$ and $21 \%$ of total added CA for the solution-cast starch films, whereas in the laboratory-scale coated starch films only up to $3.5 \%$ of total added CA was di-esterified corresponding to a DDE of 0.01 . Hence, there were large differences in di-ester content between solution-cast films and laboratory-scale coated papers. In general, the formation of di-ester between starch and CA was enhanced by high temperature curing. This has been described previously ${ }^{12,15}$ and has been attributed to the reaction mechanism of ester formation, where water evaporation shifts the reaction towards the ester production of starch. In laboratory-scale coatings 
fewer CA di-esters were generated, probably due to the shorter curing time (90 s) at a temperature where cross-linking, i.e., ester formation, is enhanced.

Pilot-scale starch coatings compared with laboratory-scale coatings

290

291

292

293

294

295

296

The starch formulation containing $30 \mathrm{pph}$ CA with an adjusted pH of 4 was scaled up in a pilot trial. In addition, the starch formulation contained 87 pph platy kaolin filler Barrisurf LX (Imerys, Cornwall, UK) and nano-sized clay filler Cloisite $\mathrm{Na}+$ (Southern Clay Products Inc., Gonzales, Texas, US) at a concentration of $3 \mathrm{pph}$. These commercial fillers were used to further improve barrier properties, e.g. WVTR. The usage of the natural montmorillonite is described in detail elsewhere ${ }^{27}$ and was not further taken into account for molecular characterization of starch. The pilot trial included both single and double layers on greaseproof paper.

\section{Scanning electron microscopy images of coating surface morphology}

Scanning electron microscopy images were taken to study the surface morphology and coverage of the carrier paper and the occurrence of pinholes and cracks. Single pilot-scale coatings (Figure 6c) had quite a smooth surface with a visible underlying fiber structure and many round pinholes (5-30 $\mu \mathrm{m})$, whereas double coating resulted in a smoother surface with less pinholes that were partly closed (Figure 6e). In comparison, the laboratory-scale coated papers prepared at $\mathrm{pH} 4$ showed no pinholes and uniform coverage of the carrier paper. There were no difference between non-cured coatings (Figure 6d) and coatongs cured at $150^{\circ} \mathrm{C}$ (Figure 6f). Pinholes in coatings can occur due to air bubbles within the starch dispersion, and hence repeated efforts were made to improve the application of the coating. For example, different defoamers provided by BIM Kemi were used to try to reduce air bubbles in the starch dispersion, which was successful for small-scale coating but not sufficient at pilot scale (data not shown). Moreover, the surface of the paper itself was not even and in a fast coating process the starch coating might not fill out the unevenness as much as in a slower process, where the starch slurry can penetrate into cavities or the like. Furthermore, irregularities in thickness can cause bursting of covered holes during the drying process. Slower drying, i.e., at a speed of 200 and $100 \mathrm{~m} / \mathrm{min}$, or using a soft blade to apply the starch did not decrease the amount of pinholes (data not shown). However, theproblem of pinholes could not be fully eliminatedand will need further investigations.

\section{Molecular changes in starch in pilot-scale coatings}

As described above, starch was extracted from the pilot-coated papers using $0.1 \mathrm{M} \mathrm{NaOH}$ solution. The $M_{W}$ was $7.4 \pm 0.63 \times 10^{5} \mathrm{~g} / \mathrm{mol}$ for single layer coatings and $8.3 \pm 0.42 \times 10^{5} \mathrm{~g} / \mathrm{mol}$ for double layer coatings. The $\mathrm{M}_{\mathrm{W}}$ of the pilot-scale coatings was slightly lower than that of the as-received starch material Solcoat P55 $\left(8.8 \times 10^{5} \mathrm{~g} / \mathrm{mol}\right)$. However, there was no significant starch degradation due to acid hydrolysis in 
pilot-scale coatings as detected by $\mathrm{M}_{\mathrm{w}}$ measurements, which was confirmed by the molecular

322 distribution (Figure 1).

323 The pilot-scale coatings had a water solubility of $43 \%$ and $67 \%$ for the single and double layer, 324 respectively. In comparison with laboratory-scale coatings prepared at pH 4 with 68\% (non-cured) and $32574 \%$ (cured) water-soluble starch, the starch in pilot-scale coated papers showed lower solubility in 326 water.

327 The $M_{w}$ in the water-soluble starch extracted from single layer pilot papers was $16.0 \times 10^{5} \mathrm{~g} / \mathrm{mol}$, while in that extracted from double layer papers it was $17.3 \times 10^{5} \mathrm{~g} / \mathrm{mol}$. This was much higher than the $\mathrm{M}_{\mathrm{W}}$ of the as-received starch material $\left(8.8 \times 10^{5} \mathrm{~g} / \mathrm{mol}\right)$. The strong decrease $(>42 \%)$ in $\mathrm{Mw}$ after de-esterification with $\mathrm{NaOH}$ implies that the starch in the water-soluble fraction was highly cross-linked. However, considering the water solubility of $43 \%$ (single layer) and $67 \%$ (double layer), only a part of the starch was represented.

The DDE of the pilot coatings was 0.024 and 0.022 for the single and double layer papers, respectively, corresponding to di-esterification of about $9 \%$ of added CA. Pilot-scale coated papers showed higher DDE values than solution-cast films at pH 4 and laboratory-scale coated films at pH 4 (Fig. 5).

One reason for these structural differences between pilot-scale coatings, laboratory-scale coatings, and solution-cast films could be the extreme differences in the drying process. In the industrial pilot-scale plant, the coated paper runs with a speed of $400 \mathrm{~m} / \mathrm{min}$ through $4 \mathrm{~m}$ long infrared dryers with high energy output and a nominal evaporation rate of $673 \mathrm{~kg} / \mathrm{m} / \mathrm{h}$. This first drying process is very short (4 s) and high-temperature $\left(150^{\circ} \mathrm{C}\right)$, followed by drying hoods at $65^{\circ} \mathrm{C}$ for about $12 \mathrm{~s}$. As the coated paper is heated rapidly and water evaporates within seconds in the air infrared dryers, this results in large differences in film formation, as seen in the microstructure revealed by the scanning electron microscopy images (Figure 6), with e.g., pinholes and uneven surface compared with laboratory-scale coatings. In addition, chemical reactions such as cross-linking and hydrolysis of starch by CA are affected. The high energy output of the infrared dryers promoted cross-linking in the starch coating but no hydrolysis occurred, probably due to the $\mathrm{pH}$ being adjusted to 4 .

Water vapor transmission rate of pilot-scale coatings compared with laboratory-scale coatings

Barrier properties in terms of WVTR were measured in both laboratory-scale and pilot-scale coatings. The results for the laboratory-scale coatings are described elsewhere ${ }^{15}$ and were used here for comparison with the barrier properties of pilot-scale coatings. The pilot-scale coatings had a WVTR of 77 and $44 \mathrm{~g} /\left(\mathrm{m}^{2} 24 \mathrm{~h}\right)$ for single and double layers, respectively. As expected, higher coat weight increased the barrier to water vapor movement. However, the laboratory-scale coated papers showed better barrier properties, with WVTR values of 16 to $41 \mathrm{~g} /\left(\mathrm{m}^{2} 24 \mathrm{~h}\right)$. One explanation could be the application of the coating, i.e. the evenness of the coat 
weight and pinholes. In laboratory-scale coating, the starch solution was metered with a wire-wound rod whereas at pilot scale a blade was used to meter out the coating. The latter could have resulted in some compression of the carrier paper, causing slightly different patterns and coat weight variations between ridges and troughs on the paper. Another reason could be shear differences beneath the blade, leading to orientation of particles, aggregation and the creation of pinholes, as seen in pilot-scale coatings (Figure 6). Hence, the laboratory-scale coated papers had slightly higher barrier properties in terms of WVTR. Such differences in transmission when conditions are scaled up have been described previously and attributed to lower coat weight due to a lower solids content in coating formulations on pilot scale. $^{28}$

\section{CONCLUSIONS}

It proved possible to extract and analyze starch from coatings on a carrier material consisting of paper. There were large differences in the molecular structure of starch between solution-cast films, laboratory-scale coatings and pilot-scale coatings, as evidenced by changes in molecular distribution, $\mathrm{M}_{\mathrm{W}}$, and degree of di-esterification. Laboratory-scale coatings showed no significant hydrolysis of starch and a lower degree of cross-linking of starch by CA compared with solution-cast films. On scaling up to an industrial pilot trial, starch coatings showed no strong hydrolysis. The degree of di-esterification was higher in pilot-scale coated papers compared with laboratory-scale coated papers and solution-cast films prepared at the same $\mathrm{pH}$. It was shown that cross-linking reactions between starch and CA were initiated in the pilot-scale coatings even though the drying period was very short, but with a high evaporation rate than in laboratory conditions. Furthermore, laboratory-scale coatings had a smoother surface morphology due to more gentle coating application compared with pilot-scale application and had better barrier properties against water vapor. Thus starch structure was differently influenced by the drying technique applied and surface morphology, in turn affecting the barrier properties of the coated paper. We believe that coated papers are more relevant than solution-cast films for studying changes in molecular structure of starch. However, further investigations are needed to determine the optimal laboratory conditions resembling industrial conditions.

\section{ACKNOWLEDGEMENTS}

Eric Olsson is highly acknowledged for preparation of solution cast films and laboratory coated papers and Gulaim Seisenbaeva for technical assistance with the scanning electron microscopy. This study was performed within the project Renewable Functional Barriers which is a part of the BFP research program, jointly launched by the Swedish Governmental Agency for Innovation Systems (VINNOVA), The Swedish Forest Industries Federation, Trä- och Möbelföretagen (TMF) and Trees and Crops for the Future (TC4F).

\section{CONTRIBUTION OF AUTHORS}


Both authors participated in planning the experimental work, evaluation of the results and revising the manuscript. The first author was responsible for the majority of the analytical work and writing the manuscript. Both authors approved the submitted and final version.

\section{REFERENCES AND NOTES}

1. Freedonia. World Green Packaging Industry, http://www.reportlinker.com/p0593473summary/World-Green-Packaging-Industry.html, 2011 (accessed March 21, 2013).

2. Reportlinker. Packaged Food Industry: Market Research Reports, Statistics and Analysis. http://www.reportlinker.com/ci02041/Packaged-Food.html (accessed November 11, 2013).

3. ; European Bioplastics/ Institute of Bioplastics and Biocomposites, EuBP market data. http://en.european-bioplastics.org/market/ (accessed November 11, 2013). 2012.

4. R. Babu, K. O'Connor and R. Seeram, Progress in Biomaterials, 2, 8 (2013).

5. M. Jamshidian, E. A. Tehrany, M. Imran, M. Jacquot and S. Desobry, Comprehensive Reviews in Food Science and Food Safety, 9, 552-571 (2010).

6. L. M. Pierce. PHA and bio-derived PE to drive bioplastic packaging market to 2020: study. http://www.packagingdigest.com/article/517396PHA_and_bio_derived_PE_to_drive_bioplastic_packaging_market_to_2020_study.php (accessed November 11, 2013), 2011.

7. I. A. Wolff, H. A. Davis, J. E. Cluskey, L. J. Gundrum and C. E. Rist, Industrial \& Engineering Chemistry, 43, 915-919 (1951).

8. P. Parovuori, A. Hamunen, P. Forssell, K. Autio and K. Poutanen, Starch - Stärke, 47, 19-23 (1995).

9. E. Olsson, M. S. Hedenqvist, C. Johansson and L. Järnström, Carbohydrate Polymers, 94, 765-772 (2013).

10. M. I. Khalil, A. Hashem and A. Hebeish, Starch - Stärke, 47, 394-398 (1995).

11. S. E. Rudolph and R. C. Glowaky. in http://www.google.com/patents?id=I-41AAAAEBAJ; U. S. Patent, Ed.; The Sherwin-Williams Company, Ohio, 1978.

12. C. Menzel, E. Olsson, T. S. Plivelic, R. Andersson, C. Johansson, R. Kuktaite, L. Järnström and K. Koch, Carbohydrate Polymers, 96, 270-276 (2013).

13. B. Ghanbarzadeh, H. Almasi and A. A. Entezami, Industrial Crops and Products, 33, 229-235 (2011).

14. N. Reddy and Y. Yang, Food Chemistry, 118, 702-711 (2010).

15. E. Olsson, C. Menzel, C. Johansson, R. Andersson, K. Koch and L. Järnström, Carbohydrate Polymers, 98, 1505-1513 (2013).

16. Å. Rindlav-Westling, M. Stading, A.-M. Hermansson and P. Gatenholm, Carbohydrate Polymers, 36, 217-224 (1998).

17. R. A. Talja. in Faculty of Agriculture and Forestry; University of Helsinki, Helsinki, 2007.

18. Å. Rindlav-Westling and P. Gatenholm, Biomacromolecules, 4, 166-172 (2003).

19. M. DuBois, K. A. Gilles, J. K. Hamilton, P. A. Rebers and F. Smith, Analytical Chemistry, 28, 350356 (1956).

20. W. R. Morrison and B. Laignelet, Journal of Cereal Science, 1, 9-20 (1983).

21. A. Altskär, R. Andersson, A. Boldizar, K. Koch, M. Stading, M. Rigdahl and M. Thunwall, Carbohydrate Polymers, 71, 591-597 (2008).

22. G. Graffmann, H. Domels and M. L. Sträter, Fette, Seifen, Anstrichmittel, 76, 218-220 (1974).

23. H. Klaushofer, E. Berghofer and R. Pieber, Starch - Stärke, 31, 259-261 (1979). 
435 24. M. Hirashima, R. Takahashi and K. Nishinari, Food Hydrocolloids, 19, 909-914 (2005).

436 25. R. E. Wing, Starch - Stärke, 48, 275-279 (1996).

437 26. Å. Rindlav, S. H. D. Hulleman and P. Gatenholm, Carbohydrate Polymers, 34, 25-30 (1997).

438 27. E. Olsson, C. Johansson and L. Järnström, Applied clay science(just accepted).

439 28. H. Kjellgren, M. Gällstedt, G. Engström and L. Järnström, Carbohydrate Polymers, 65, 453-460

440 (2006).

441

442 